\title{
Herpetofaunal Inventories of the National Parks of South Florida and the Caribbean: Volume IV. Biscayne National Park
}

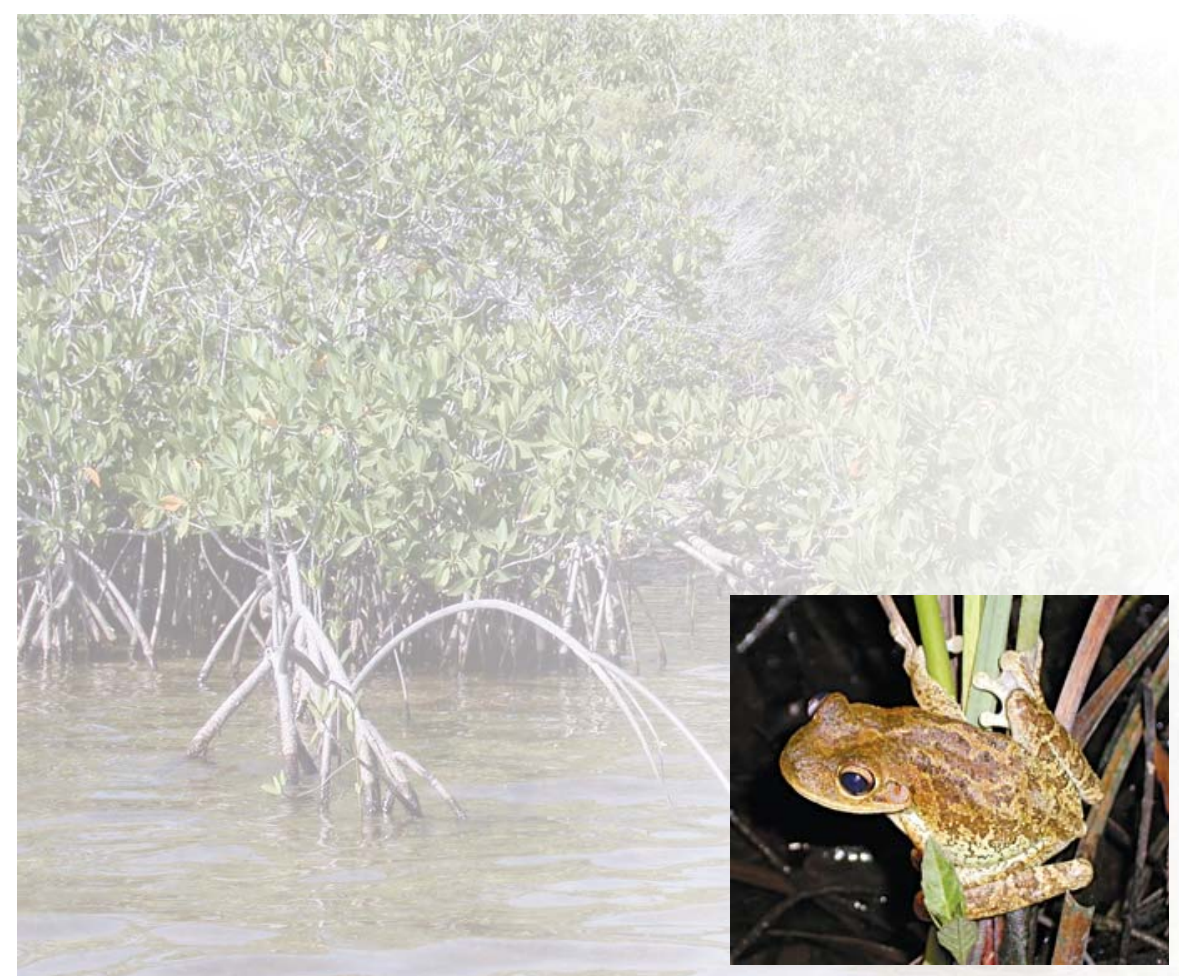

Open-File Report 2007-1057

U.S. Department of the Interior

U.S. Geological Survey 